\title{
Proceeding
}

Supplementary Issue: Winter Conferences of Sports Science. International Conference of Engineering, Innovation Technology and Applied Science.

\section{The impact of international society on mental health, performance and development of athlete}

\author{
VICTORIA YERMILOVA 14 , SVETLANA MALTSEVA¹, GULSINA MURTAZINA¹, ANDREI SHULZHENKO², \\ KONSTANTIN ZAKHAROV1 \\ ${ }^{1}$ Lesgaft National State University of Physical Education, Sport and Health, St. Petersburg, Russian \\ Federation \\ ${ }^{2}$ Russian State University of Tourism and Service, Moscow, Russian Federation
}

\begin{abstract}
The purpose of this study is to identify the effect of anti-doping control on athletes' performance indicators. The authors have monitored 86 combined track and field events athletes who have been preparing for the competition for 6 months. Athletes have been divided into two groups: group I includes athletes that have not been subjected to doping control $(n=42)$, and athletes of group II $(n=44)$ have experienced such a control a month before the competition. Levels of insulin, cortisol, glucose in the blood serum have been determined for athletes to assess the intensity of stress reactions. The HOMA Index, the ratio of cortisol/insulin, and the Baevsky index have been calculated. Sports achievements have been measured on a 100-point scale of the average result of the team in such types of competitions as running, shooting, swimming, standing long jump, a hammer throw. In group II athletes, after doping control, the level of cortisol has increased by 1.9 times $(p<.05)$ compared to the initial level and remained 1.7 times higher before the competition. A significant increase in glucose, insulin and HOMA index has been observed among athletes of II group. In this group, the value of the Baevsky index after doping control has increased by 2.9 times compared with the initial value $(p<.05)$. Before the competition, the Baevsky index remained 2.6 times higher $(p<.05)$. Representatives of the first group have not shown a statistically significant difference between performance in the training period and in the competitions. Athletes of the second group have shown a decrease in results in competitions compared to the initial level of training. A correlation is observed between the value of the Baevsky index and the average team performance indicator in running $100 \mathrm{~m}(r=-0.76, p<.05)$, running $2000 \mathrm{~m}(r=-0.68, p<.05)$ shooting $(r=-0.52, p<.05)$ and long jumps $(r=-0.53, p<.05)$. Carrying out selective indicative doping control leads to a stress response in the target group, which turns into prolonged stress, leading to a significant decrease in the performance indicators of athletes. Keywords: Stress; Doping control; Baevsky index; Combined events athletes; Stress response.
\end{abstract}

Cite this article as:

Yermilova, V., Maltseva, S., Murtazina, G., Shulzhenko, A., \& Zakharov, K. (2020). The impact of international society on mental health, performance and development of athlete. Journal of Human Sport and Exercise, 15(2proc), S370-S378. doi:https://doi.org/10.14198/jhse.2020.15.Proc2.28

Corresponding author. Lesgaft National State University of Physical Education, Sport and Health, St. Petersburg, Russian Federation.

E-mail: victoriayermilova@rambler.ru

Supplementary Issue: Winter Conferences of Sports Science. International Conference of Engineering, Innovation Technology and Applied Science.

JOURNAL OF HUMAN SPORT \& EXERCISE ISSN 1988-5202

(c) Faculty of Education. University of Alicante

doi:10.14198/jhse.2020.15.Proc2.28 


\section{INTRODUCTION}

In modern sport, especially in the active training period, athletes are subjected to the greatest loads, which inevitably cause the corresponding reactions of the body (llyin, 2012; Chernykh \& Borisenko, 2016). Each competition, as well as the stage of preparation for it, can be considered a period of increased stress load (Kurashvili, 2008).

Stress is a complex process with physiological and psychological components (Vodopyanova, 2009; Carless \& Douglas, 2013; Samoilov, 2015a; 2015b). The changes that occur in the athlete's body are caused not only by the physiological effects of the loads (Abramova \& Ivankova, 2016; Fedorchuk et al., 2017). More important are psychological influences, especially motivational ones. During the competition, the athlete creates emotional models of situations such as victory or defeat, disqualification, etc., which ultimately leads to the creation of tension that will affect his/her future results (Caddick \& Smith, 2014; Rastokin et al., 2019). It also depends on the individual reaction to the stress factors (Kaiseler et al., 2009; Stănescu \& Vasile, 2014).

It is proved that the athlete's performance in competitions depends not only on the level of training, but also on the emotional state (Hudson \& Day, 2012; Fedorchuk et al., 2018). There are many cases when welltrained athletes who show high results in training, but at the competitions themselves show much lower results due to the influence of stress, overexcitement or banal anxiety, which they cannot cope with (Shinkaruk et al., 2017).

The most common cause of stress is known to be an emotional stimulus (Astalos et al., 2012; Wagstaff et al., 2013). In sports, it can be trauma, overwork, competition, a moral climate in the team, as well as conducting various checks, including doping control (Sallen et al., 2018).

The essence of doping control is to study an athlete's bioassay to determine if he/she has traces of prohibited substances and to establish the use of prohibited methods of preparation for competitions (Korzh \& Bashkin, 2006; Zaksaite \& Radke, 2014; Sumner, 2017). In recent years, the spread of doping use has become one of the key issues in sports, pushing aside other issues of complexity and contradiction (Backhouse et al., 2014; Engelberg et al., 2015).

Scantily studied and of scientific interest is the impact of doping controls on the psychological state of athletes and, as a consequence, on the effectiveness of competitions (Ulrich et al., 2017). Let us consider stress factors and trace their influence on the condition of athletes (Merkibayev et al, 2018).

Purpose of this study - to study the effect of doping control and, as a result, prolonged stress on athlete's performance indicators; to study changes in biochemical stress markers in a study group.

\section{MATERIALS AND METHODS}

The authors have monitored 86 combined events athletes, who have been preparing for the competition for 6 months. Athletes have been divided into two groups, equivalent in terms of training: group I has included those who have not been subjected to doping control $(n=42)$, and athletes of group II $(n=44)$ a month before the competition experienced doping control. The control group has consisted of 20 healthy individuals who have not been exposed to stress factors throughout the study period. 
Athletes from the study groups have been examined for stress levels at the beginning of training, after doping control in group II and before the competition. At these stages, the levels of insulin, cortisol, glucose in the blood serum have been studied to assess the intensity of stress reactions, the HOMA (Homeostasis Model Assessment) index has been calculated. Glycemia has been determined using a One touch ultra-glucose meter, and the concentration of cortisol and immunoreactive insulin (IRI) in blood serum has been determined by the enzyme immunoassay.

The HOMA index, which reflects the level of insulin resistance, which increases with stress reactions, has been calculated using the generally accepted formula: NOMA $=($ glycemia $(\mathrm{mmol} / \mathrm{I}) \cdot \mathrm{IRI}(\mu \mathrm{IU} / \mathrm{ml})) / 22.5$, where $I R I$ is immunoreactive insulin. The ratio of cortisol/insulin (C/I) has been calculated, which, according to L.E. Panin is the most objective criterion for the activity of compensatory processes that develop in the body in response to stress.

To determine the level of stress, monitoring has been carried out, which included: pulse oximetry, heart rate, mean blood pressure, capnometry. The following parameters of cardiointervalogramm have been subject to analysis:

- $\quad$ Mode (Mo) - value of cardio interval (ms), which is most often found in a given time series;

- $\quad$ Mode amplitude (AMo) - share (\%), which corresponds to the mode values;

- $\quad$ Variational range (VR) - the difference between the maximum and minimum values of the cardio intervals (ms);

- $\quad$ The Baevsky stress index, calculated by the formula: Baevsky index $=$ AMo/2 $\bullet$ Mo $\bullet$ VR (Baevsky et al., 1984).

Sports achievements have been measured on a 100-point scale of the average team result in such types of competitions as running, shooting, swimming, long jumps, a hammer throw.

The results have been processed statistically using software - the Microsoft Excel spreadsheet processor and the Statistica 10.0 application software package (StatSoft, USA). The main statistical parameters have been calculated: arithmetic mean (M) and its average error $( \pm m)$, confidence coefficient $(p)$, Spearman's correlation coefficient (r).

\section{RESULTS}

When examining the hormonal state of both groups of athletes, it is found that the difference between the levels of cortisol in the blood is not significant among the study groups at the beginning of training (Table 1). Immediately after doping control, the cortisol level in athletes of the first group has been $9.3 \%$ higher than the initial $(p<.05)$. Before the competition, this indicator was $17.0 \%$ higher than the initial one and $7.8 \%$ higher than the level measured after doping control in group II $(p<.05)$. This indicates a moderate increase in tension during the training period and highly increased tension closer to the competition.

In group II athletes, the level of cortisol after doping control has increased by 1.9 times $(p<.05)$ compared to the level at the beginning of training and decreased by $11.0 \%$ before the start of the competition but remained 1.7 times higher than in the initial level $(p<.05)$. This indicates an acute stress response to doping control and prolongation of stress until the competition. 
Table 1. Dynamics of stress markers in study groups.

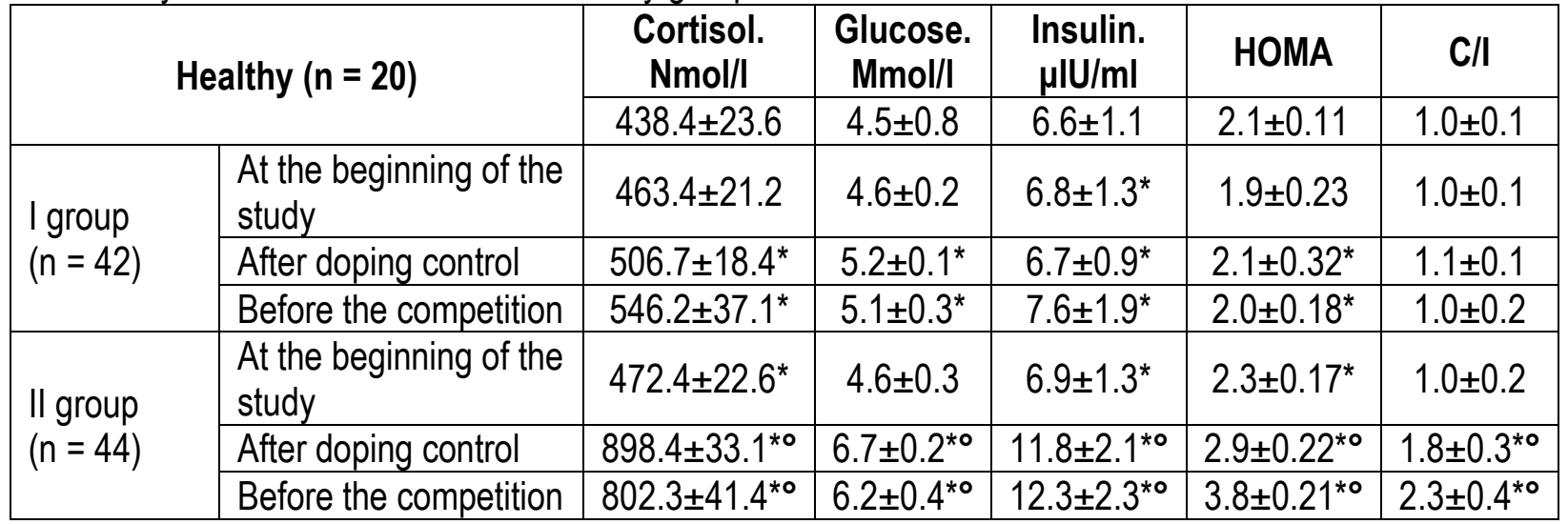

Notes: * - The accuracy of the differences compared to healthy $(p<.05)^{\circ}$ - The probability of differences in indicators for group 1 $(p<.05)$.

The glucose level in the blood of group I athletes fluctuated within normal limits during all measurements. The glucose level in the blood of athletes of group II sharply increased 1.5 times after doping control $(p<.05)$ and was 1.4 times higher than the initial level just before the competition $(p<.05)$.

The insulin level in group I was slightly higher than in the control group in all three measurements. In the second group of the study, insulin level after doping control increased 1.7 times $(p<.05)$ compared to the initial level and was 1.8 times higher than its level at the beginning of the competition $(p<.05)$.

The authors have also observed an increase in the HOMA index among athletes of group II in the second and third measurements. The ratio of cortisol/insulin among the athletes of group I did not significantly differ from that in the control group. Among the representatives of group II after doping control this ratio was 1.8 times higher than at the beginning of training $(p<.05)$ and increased by $27.8 \%$ before the competition $(p<$ $.05)$.

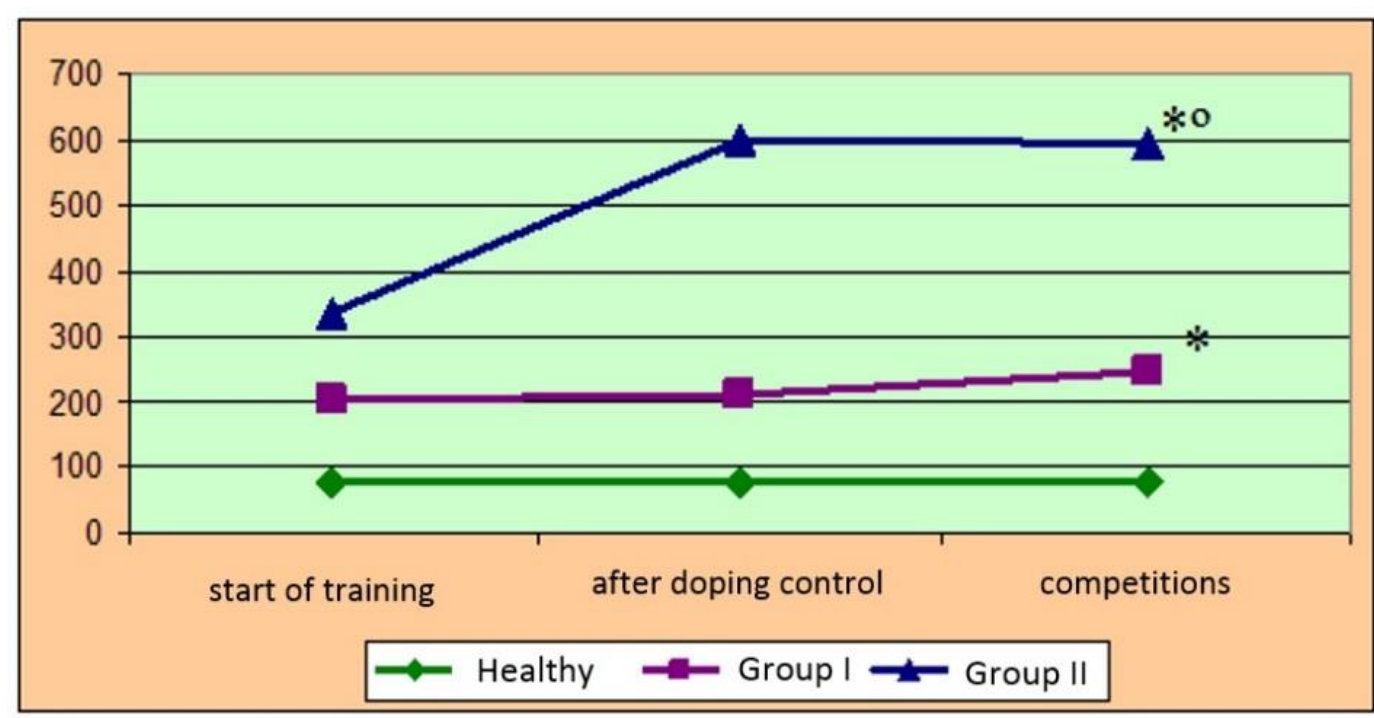

Notes: ${ }^{*}$ - The accuracy of the differences compared to healthy $(p<.05)^{\circ}$ - The probability of differences in group I $(p<.05)$.

Figure 1. Comparative assessment of the Baevsky index dynamics in study groups. 
The Baevsky stress index among athletes of group I indicates the compensated distress (Figure 1). At the beginning of training, the Baevsky index was 124, in the second measurement it was slightly increased, and before the competition, its value was $35.4 \%$ higher than in the initial measurement $(p<.05)$, which is a normal reaction at this stage.

In the second group of the study, the stress index after doping control increased by 2.9 times compared with what was at the beginning of the training period $(p<.05)$. Before the competition, the Baevsky index in this group still remained 2.6 times higher than the initial value $(p<.05)$.

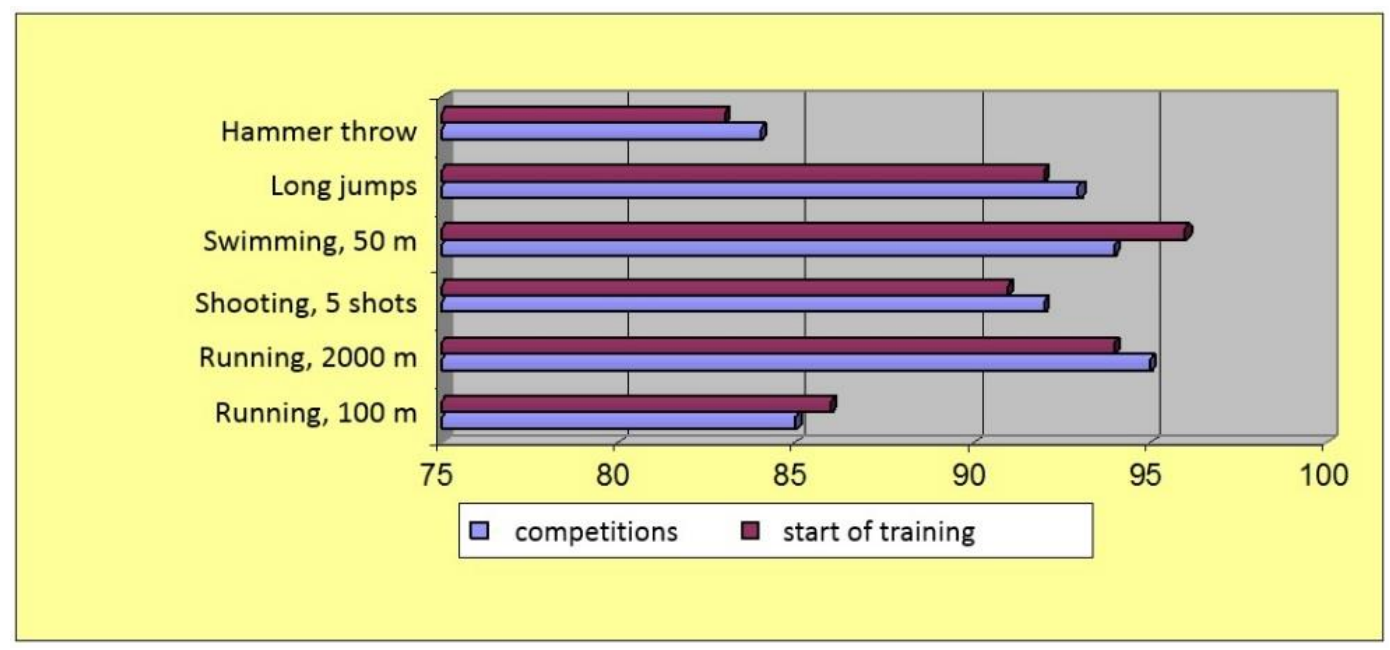

Figure 2. Dynamics of sports achievements of group I.

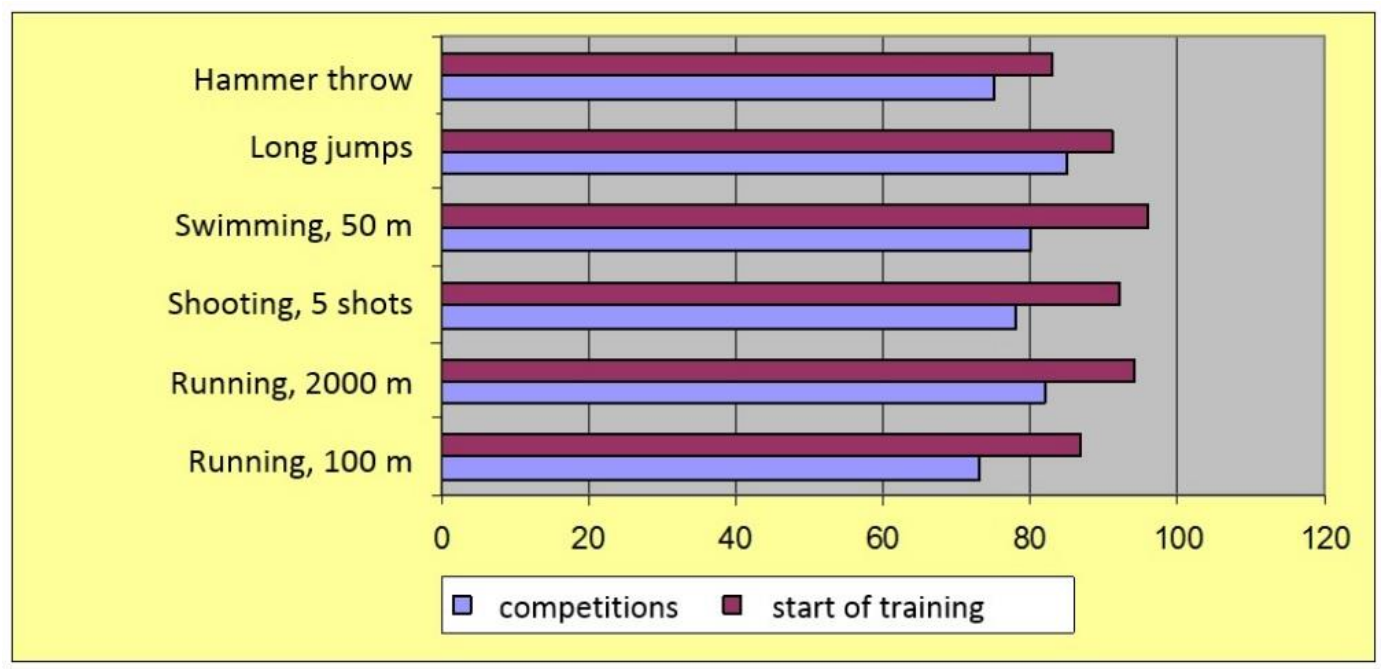

Figure 3. Dynamics of sports achievements of group II.

According to the performance indicators of the combined events athletes, the representatives of the first group do not show a statistically significant difference between performance in the training period and in the competitions themselves (Figure 2). Athletes of the second group show a decrease in results in competitions compared to the initial level of training. Points in the $100 \mathrm{~m}$ run are $16.0 \%$ lower than in the initial 
measurements $(p<.05)$, in the $2000 \mathrm{~m}$ run athletes show a 14.6\% lower result $(p<.05)$. In shooting and long jumps, the results of the competition are $6.9 \%$ and $7.0 \%$ lower than at the beginning of training, respectively $(p<.05)$ (Figure 3 ).

A correlation is also observed between the Baevsky index and the average team performance indicator in running $100 \mathrm{~m}(r=-0.76, p<.05)$, running $2000 \mathrm{~m}(r=-0.68, p<.05)$, shooting $(r=-0.52, p<.05)$ and long jumps $(r=-0,53, p<.05)$.

\section{DISCUSSION}

The increase in the level of biochemical indicators of stress, such as cortisol, glucose and insulin, among athletes of the first group should be regarded as an adaptive reaction of the body to increased physical activity. The level of these indicators was gradually increasing and was of greatest importance before the competition. This indicates a moderate increase in tension during the training period and highly increased tension closer to the competition. According to the results of some studies, it can be argued that competition is the most severe stress for an athlete (Paluska \& Schwenk, 2000). Here, the main stimulus is the realization that the winning or failing result depends on the quality of fulfilling the tasks. A study of the state of athletes before the competition shows that about $13 \%$ of the study participants have been in a state of high stress, $86.3 \%$ have experienced a state of severe stress (Voronova et al., 2012).

Sports require not only physical, but also psychological potential. Using internal resources, athletes experience significant tension, which leads to stress, which is an integral part of sports (Howells \& Fletcher, 2015).

However, the general stress level, which was determined using the Baevsky index, indicated that although the athletes of the first group experienced a certain tension, however, it did not affect the physiological processes that were directly related to professional performance.

After the demonstrative and selective doping control, in the athletes of the second group, biochemical stress markers increased sharply. The general stress index testified to the influence of the psychological state on the functional ability of the body and overall performance. This level of tension lasted for a whole month and reached its maximum before the competition. The psychological atmosphere in the training place among the athletes played a decisive role in reducing the performance indicators of the participants in this group. Doping control was an additional external stress factor.

Many authors have noted the existence of double standards and the defencelessness of athletes in front of doping services. There are practically no cases of successful appeals based on the results of doping control, which equates such decisions to a sentence. Violation of a person's right to non-interference in the state of his/her body, the inadmissibility of forced tests, create psychological pressure on athletes (Ledashin et al.,, 2003).

In numerous works, one may find many allegations that the observance of the ethical aspect of doping control is of great importance. Strict sampling regulations, easy access of commissions to the athletes' place of residence exert great psychological pressure. The author claims that restricting the athlete's personal rights and freedoms and his/her personal life creates only additional emotional stress. The latter serves as a trigger to reduce the level of mental and physical performance (Platonov, 2016). 
The idea of the risk of disqualification and its consequences becomes intrusive and turns into a kind of phobia. Athlete activities currently require a lot of professional endurance, time and energy costs and almost complete dedication. According to Platonov V.N., all this is already a heavy burden that falls on an athlete. Therefore, the risk of sudden and peremptory loss of achievements can negatively affect the health of athletes or cause depression.

A similar effect of certain external factors on the psychological state of athletes was also observed (Alyoshicheva, 2016). This study found a high level of anxiety among professional athletes in extreme sports before the competition. This was due to the fact that the athletes fought for a certain prize and the risk of losing became an external stimulus, causing a pronounced stress response.

In the current study, the fact of selective control and the risk of being disqualified or discredited created a negative psychological background, which led to the fact that athletes showed much lower results than the team of the first group. Although there was no significant difference between the initial training levels of both groups.

\section{CONCLUSIONS}

1. Carrying out selective indicative doping control leads to a stress reaction in the target group, which turns into prolonged stress. The latter manifests in an increase in the level of cortisol, glucose and insulin in the blood, an increase in the HOMA index and the ratio of cortisol/insulin. The levels of these indicators increased after doping control and remained elevated before the competition.

2. Prolonged stress leads to a significant decrease in the performance indicators of athletes: in the 100 and 2000 meters run, they decreased by $16 \%$ and $14.6 \%$, respectively $(p<.05)$. A negative correlation between the stress index and the achievements of athletes in various categories of combined events was revealed.

3. Selective and indicative doping control acts as a stressful external factor, which leads to destabilization of athletes' mental health, which requires correction, since it has a negative effect on their performance.

\section{REFERENCES}

Abramova, V.V., \& Ivankova, Yu.A. (2016). Ways to overcome stress by athletes in competitive sports. Scientific Result. Pedagogy and psychology of education, 4(10).

Alyoshicheva, A.V. (2016). Psychological health of professional athletes involved in extreme sports. Bulletin of Kemerovo State University, 3(67).

Astalos, M., Wijndaele, K., Bourdeaudhuij, I. De, Philippaerts, R., Matton, L., Duvigneaud, N., Thomis, M., Lefevre, J., \& Cardon, G. (2012). Sport participation and stress among women and men. Psychology of Sport and Exercise, 13, 466-469. https://doi.org/10.1016/j.psychsport.2012.01.003

Backhouse, S. H., Collins, C., Defoort, Y., McNamee, M., Parkinson, A., Sauer, M., ... \& Horta, L. (2014). Study on Doping Prevention: a Map of Legal, Regulatory and Prevention Practice Provisions in EU 28. Luxembourg: Publications Office.

Baevsky, R.M., Kirilov, O.I., \& Kletskin, S.Z. (1984). Mathematical analysis of changes in heart rate during stress (pp. 219). M.: Nauka (Science).

Caddick, N., \& Smith, B. (2014). The impact of sport and physical activity on the well-being of combat veterans: A systematic review. Psychology of Sport and Exercise, 15, 9 - 18. https://doi.org/10.1016/i.psychsport.2013.09.011 
Carless, D., \& Douglas, K. (2013). Living, resisting and playing the part of athlete: Narrative tension in elite sport. Psychology of Sport and Exercise, 14, 701 - 708. https://doi.org/10.1016/i.psychsport.2013.05.003

Chernykh, Z.N., \& Borisenko, T.M. (2016). Sports activities as a means for students to deal with stress. Bulletin of Shadrinsk State Pedagogical University, 2(30).

Engelberg, T., Moston, S., \& Skinner, J. (2015). The final frontier of anti-doping: a study of athletes who have committed doping violations. Sport Manag. Rev., 18, 268-279. https://doi.org/10.1016/j.smr.2014.06.005

Fedorchuk, S.V., Tukaev, S.V., Lysenko, E.N., Shinkaruk, O.A., \& Voronova, V.I. (2017). The psychophysiological state of athletes with different levels of personal and situational anxiety in complex coordination sports. Sports medicine and physical rehabilitation, 1, 26-32.

Fedorchuk, S., Tukaiev, S., Lysenko, O., \& Shynkaruk, O. (2018). The psychophysiological state of highly qualified athletes performing in diving with different levels of anxiety. European Psychiatry, Elsevier, $48,681$.

Howells, K., \& Fletcher, D. (2015). Sink or swim: Adversity and growth-related experience in Olympic swimming champions. Psychology of Sport and Exercise, 16, 37 - 48. https://doi.org/10.1016/i.psychsport.2014.08.004

Hudson, J., \& Day, M.C. (2012). Athletes' experiences of expressive writing about sport stressors. Psychology of Sport and Exercise, 13, 798 - 806. https://doi.org/10.1016/j.psychsport.2012.05.005

Ilyin, E.P. (2012). Psychology of sport: textbook (pp. 352). SPb.: Peter.

Kaiseler, M., Polman, R., \& Nicholls, A. (2009). Mental toughness, stress appraisal coping and coping effectiveness in sport. Personality and individual differences, 47, 728 - 733. https://doi.org/10.1016/i.paid.2009.06.012

Korzh, V.P., \& Bashkin, I.N. (2006). Doping yesterday, today and tomorrow (pp. 9-16). Nikolaev: Stepinfo.

Kurashvili, V.A. (2008). Psychological training of athletes. Innovative technologies (pp. 114). M.: "MediaLabProekt".

Ledashin, D., Kharitonova, A., \& Khrushchev, V. (2003). Medal with ephedrine. Top Secret, 10, 30-31.

Merkibayev, T., Seisenbayeva, Z., Bekkozhanova, G., Koblanova, A., \& Alikhankyzy, G. (2018). Oppositions in the conceptual and linguistic category of time. Opción, 34(85-2), 116-148.

Paluska, S.A., \& Schwenk, T.L. (2000). Physical activity and mental health: current concepts. Sport Medicine, 29(3),167 - 180. https://doi.org/10.2165/00007256-200029030-00003

Platonov, V.N. (2016). Doping in Olympic sports: crisis phenomena and ways to overcome them. Theory and practice of physical culture, 10, 94-98.

Rastokin, N.A., Zagretdinova, O.O., \& Orekhovskaya, E.V. (2019). The effect of stress on the competitive activity of an athlete and methods of self-regulation. Innovative Science, 5 .

Sallen, J., Hirschmann, F., \& Herrmann, C. (2018). Evaluation and Adaptation of the Trier Inventory for Chronic Stress (TICS) for Assessment in Competitive Sport. Frontiers in Psychology, 9(308). https://doi.org/10.3389/fpsyg.2018.00308

Samoilov, N.G. (2015a). Factors affecting the success of athletes in extreme conditions. Essays on legal and extreme psychology: a collection of scientific papers (pp. 201-206). Ryazan.

Samoilov, N.G. (2015b). Objective and subjective factors on which the extremeness of a sport and athletic performance depend. Essays on legal and extreme psychology: a collection of scientific papers (pp. 115-120). Ryazan.

Shinkaruk, A., Lysenko, A., \& Fedorchuk, S. (2017). Stress and its impact on the competitive and training activities of athletes. Physical Culture, Sports and Health of the Nation: Collection of scientific works, 3(22), 469-476. 
Stǎnescu, M., \& Vasile, L. (2014). Using Physical Exercises to improve Mental Health. Procedia-Social and Behavioral Sciences, 149, 921 - 926. https://doi.org/10.1016/j.sbspro.2014.08.289

Sumner, C. (2017). The spirit of sport: the case for criminalisation of doping in the UK. Int. Sports Law J., 16, 217-227. https://doi.org/10.1007/s40318-016-0103-2

Ulrich, R., Pope, H. G., Cléret, L., Petróczi, A., Nepusz, T., Schaffer, J., ... \& Simon, P. (2018). Doping in two elite athletics competitions assessed by randomized-response surveys. Sports medicine, 48(1), 211-219. https://doi.org/10.1007/s40279-017-0765-4

Vodopyanova, N. E. (2009). Psychodiagnosis of stress (pp. 336). St. Petersburg: Peter.

Voronova, V., Smolyar, I., \& Kovalchuk, V. (2012). Features of overcoming stress in Olympic athletes using coping strategies. Physical education, sport and health culture in modern society: Collection of scientific papers, 4 (20), 411-414.

Wagstaff, Ch., Hanton, S., \& Fletcher, D. (2013). Developing emotion abilities and regulation strategies in a sport organization: An action research intervention. Psychology of Sport and Exercise, 14, 476 - 487. https://doi.org/10.1016/j.psychsport.2013.01.006

Zaksaite, S., \& Radke, H. (2014). The interaction of criminal and disciplinary law in doping-related cases. Int. Sports Law J., 14, 115-127. https://doi.org/10.1007/s40318-014-0045-5

\section{(C)}

This work is licensed under a Attribution-NonCommercial-NoDerivatives 4.0 International (CC BY-NC-ND 4.0). 